\title{
Seismic Vulnerability Assessment of Buildings in GIS Environment: Dhankuta Municipality, Nepal
}

\author{
Basanta Paudel \\ Master's Student \\ and \\ Pushkar K Pradhan \\ Professor, Head, \\ Certral Department of Geography \\ pushkar.pr@gmail.com
}

\begin{abstract}
This study was carried out to assess the Seismic vulnerability of buildings in Dhankuta municipality. It includes estimating probable building damage at different intensities for certain earthquake scenario. This study has three-fold objectives. At first, nature and types of buildings were identified based on field survey and then probable buildings damage condition under different earthquake scenarios was assessed based on GIS built different hazard layers. Lastly, factors responsible for increasing risk of building vulnerability was identified based on existing studies. The building information of 4287 both residential and non residential buildings and 7849 separate floor were collected. Among them, 82.79 percent floors were used for residential purpose, 7.86 percent for commercial purpose and 9.35 percent for other purposes. Most of these buildings were constructed with stone in mud mix. Around 51.4 percent buildings were built 20 to 50 years ago. The building vulnerability in different earthquake scenario is assumed at different intensities. The assessment of vulnerability of building, building damage matrix, GIS and seismic intensity map were used. To estimate the buildings damage three earthquake scenario i.e. Udayapur, North-Sunsari and South-Sunsari earthquake scenarios were used. It is estimated that if Udayapur earthquake strike the municipality $14.21 \%$ of the total buildings will totally collapse the rest $83.33 \%$ will be partially damaged. The ward number 7, 6, 1, and 5 have buildings with high vulnerability due to old buildings, building attached and some parameters of construction materials. This study recommends that awareness programme about how to make buildings safe from earthquake be lunched by the responsible agencies such as municipality.
\end{abstract}

Key words: Seismic vulnerability, earthquake hazard, building characteristics, factors of vulnerability

\section{Introduction}

The damage of life and property caused by different natural hazards like landslide, flood, storm, drought, earthquake are extremely high (Khanal 1996). Vulnerability is a set of conditions and 
process resulting from physical, social, economical and environmental factors which increase the susceptibility of a community to the impact of hazards (UNDP 2004). Positive factors that increase the ability of people and the society they live in to cope effectively with hazards that increase their resilience or reduce their susceptibility are considered as capacities. An earthquake is a sudden shift or movement of the earth's crust caused by the release of stress accumulated along geologic faults or volcanic activity (Pandey 1999).

The high seismicity of Nepal is related to the presence of active faults between tectonic plates along the Himalayas, such as the Main Boundary Fault (MBT) and Main Central Thrust (MCT). Nepal has experienced a number of great earthquakes; the most dreadful being the one in the year 1934 AD, which was of 8.4 magnitude on the Richter scale and then the 1980 earthquake with epicenter in Bajhang district that destroyed more than 2,500 houses. Another major earthquake of 1988 had its epicenter in Udayapur and measured 6.6 Richter scale and killed more than 7,000, injured 6,000 people, caused the collapse of 22,000 houses. From 1971 to 2003 , about 34,000 buildings were destroyed and 56,000 were damaged by earthquake. More than 126 million dollar was lost during this period (NSET 2004).

Earthquake usually originates some miles beneath the surface, and from the origin or seismic focus the vibrations spread in all directions. They reach the surface first at the point immediately above the origin and this point is called the epicenter. It is at the epicenter where the shock of the earthquake is first experienced, and on the ground it seems to spread outwards on wave spread form a stone thrown into a pool of water (Lake 2006). Here an attempt is made to assess the vulnerability condition of buildings, and its probable reasons in Dhankuta, which is one of the probable earthquake hazard prone areas of Nepal.

\section{Research methodology}

Dhankuta is a district headquarters, as well as a regional centre of eastern development region of Nepal (Fig. 1). Situated between $26^{\circ} 59^{\prime} 59^{\prime \prime}$ and $27^{\circ} 02^{\prime} 55^{\prime \prime}$ north latitude and $87^{\circ} 17^{\prime} 52^{\prime \prime}$ and $87^{\circ} 23^{\prime} 09^{\prime \prime}$ east longitudes, this hill town covers an area of $48.74 \mathrm{~km}^{2}$. The elevation ranges from $250 \mathrm{~m}$ to 2,144 masl. The municipality has 20,668 people, with a density of 9 persons per $\mathrm{km}^{2}$.

\section{Earthquake hazard scenario in Dhankuta municipality}

There are different types of active faults found near by the Dhankuta municipality area. Among them, two active faults of Main Boundary Thrust (MBT) and one active fault of Himalayan Frontal Fault (HFF) are chosen to estimate intensity scenario of building damage and collapse. Three different earthquake scenarios, namely Udayapur Earthquake, NorthSunsari Earthquake and South-Sunsari Earthquake are used to estimate intensity and building vulnerability. The main characteristics and direction of these earthquakes faults are shown in table 1 and figure 2 .

Figure 1: Location of Dhankuta Municipality, Nepal

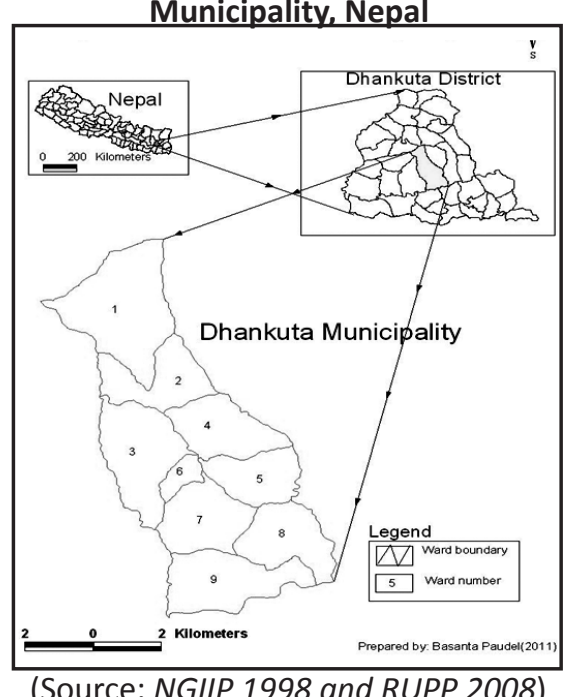


Seismic Vulnerability Assessment of Buildings in GIS ... - Basanta Paudel and Pushkar K Pradhan

Table 1: Earthquake Scenarios in Dhankuta municipality

\begin{tabular}{llll}
\hline Earthquake Name & Udayapur & North Sunsari & South Sunsari \\
\hline Fault Name & Main Boundary & Main Boundary Thrust & Himalayan Frontal \\
Magnitude & Thrust & 7.5 & 7.2 \\
Distance & 8.0 & $10 \mathrm{~km}$ & $13.5 \mathrm{~km}$ \\
Depth & $33.0 \mathrm{~km}$ & $20 \mathrm{~km}$ & $20 \mathrm{~km}$ \\
Direction & $20 \mathrm{~km}$ & South & South \\
\hline
\end{tabular}

Source: BCDP 2008

The Himalayan frontal fault is located in southern part of Dhankuta and as such it is named South-Sunsari earthquake. Although all three types differ in terms of their magnitude, distance and direction, depth of $20 \mathrm{~km}$ is considered for all the analyses. Magnitude value of those earthquake faults is already defined by BCDP project. The distance is measured from grid id number 556 of the study area to the nearest point of the earthquake with the help of GIS tool. Direction name is also defined by watching study area and location of the fault line.

Figure 2: Distance and direction of earthquake scenario

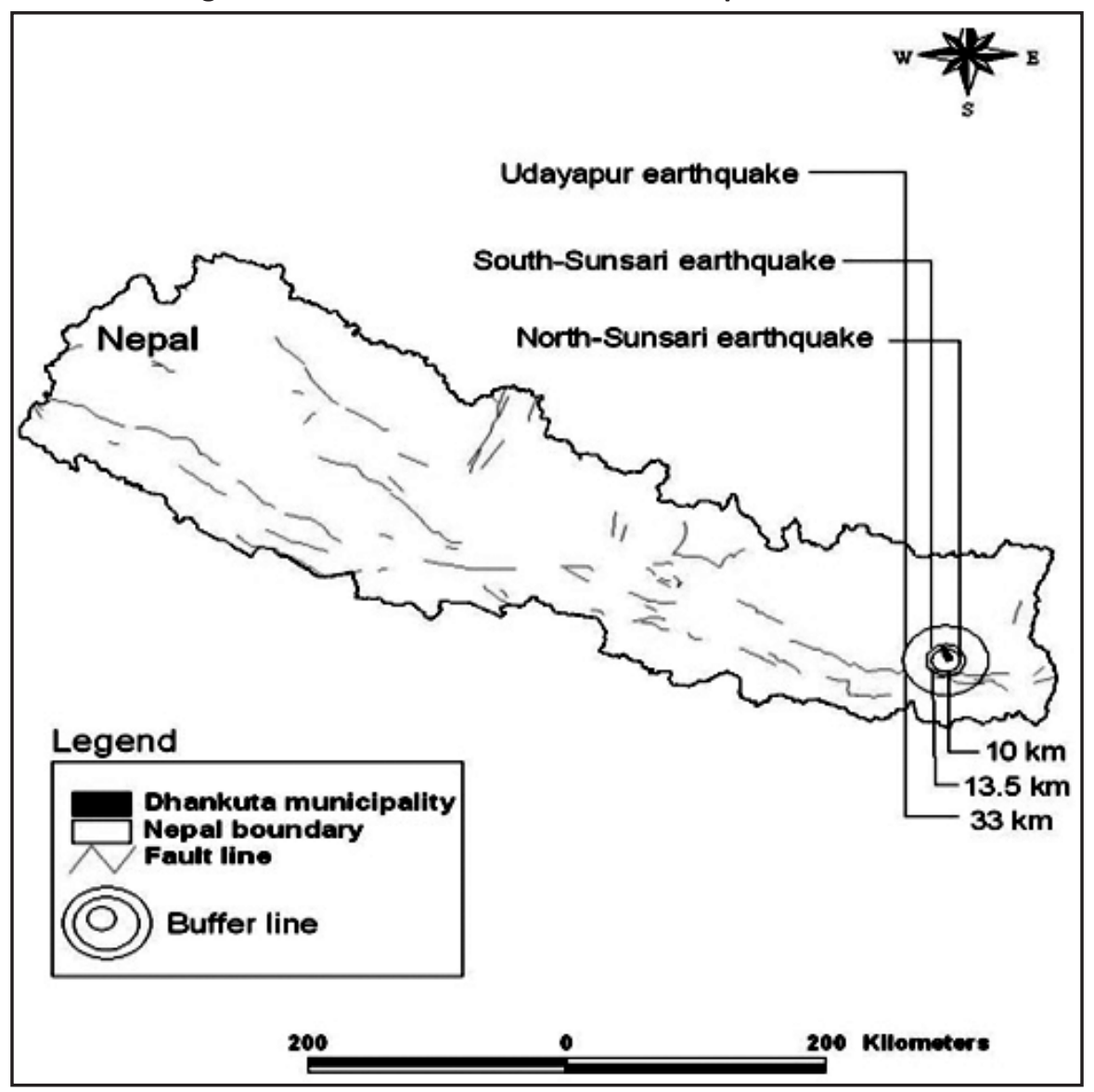

(Source: BCDP 2011) 


\section{Intensity Distribution}

The (Udayapur) earthquake is anticipated to occur due to the active main boundary thrust fault which lies about $33 \mathrm{~km}$ that correspond south-west from the Dhankuta municipality which is regarded as huge earthquake at 8.0 magnitudes. Figure 6 shows earthquake scenario having higher VIII intensity range in ward 2 and 6 . Similarly, the lowest intensity range represents in ward no. 8 and 9. Similarly, North-Sunsari earthquake scenario is taken as second possible hypothetical scenario and South-Sunsari earthquake scenario is assumed to be the third probable hypothetical earthquake for this study area.

Figure 2: Distance and direction of earthquake scenario

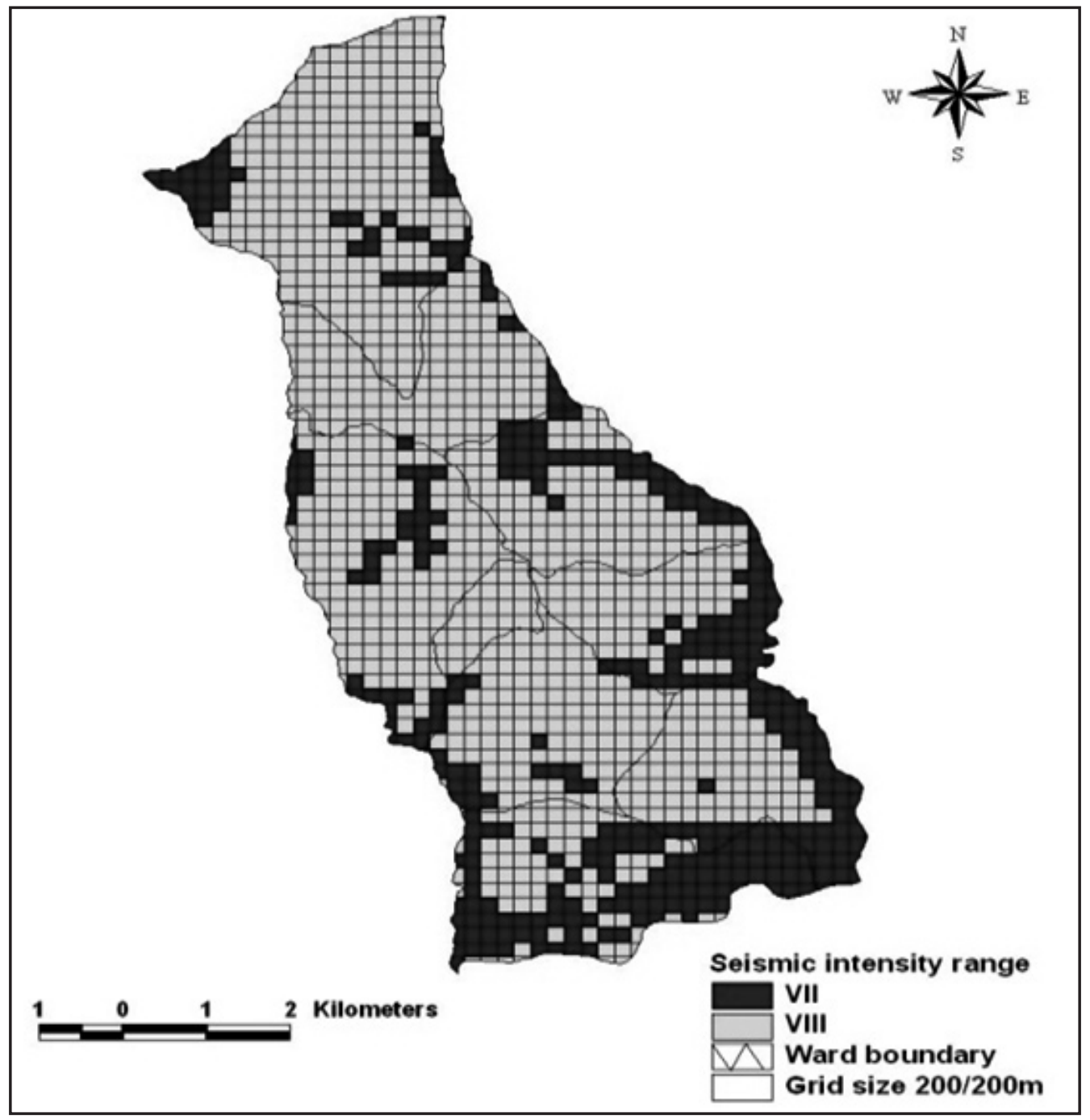

(Source: Timsina 2008) 
The research area has been divided into different grids on 200/200m size. ID number 556 is base grid for measuring nearest fault line distance. The intensity map of the research area mainly lies in the intensity VII and VIII on the basis of geological condition, seismic hazard contour map, buildings different parameters, fault line distance, direction, and magnitude.

\section{Research Methodology}

The whole research work has been divided into three major parts.

\section{Pre field work}

The pre-field work included review of previous research about earthquake loss estimation and related. Google image was used as the main base image to delineate the building units in the field. The study area was divided into 12 different blocks and the resulting image printed on large scale to locate the buildings in the field area. Inventory sheet was used to collect information on different building parameters like geometry, height, age soft story, building material, cantilever, building separation, attachment of other buildings, non-structural elements such as water tank, mobile and other tower, overhead water tank etc.

\section{Field work}

The field work was conducted for a month from January to February 2011. During the field survey individual buildings were identified and traced in the Google image with shape and given building ID. The buildings which were not identified in the field but shown in the image were deleted and newly constructed buildings were added on the image and along with it large building polygons were separated. The drawing of new buildings and the separation of large building polygons into separate building units was done manually with care so that more precision could be achieved. Other information like building type, construction materials, age, geometry, buildings shape, roofs, and cantilever of each building were recorded in the building inventory sheet. Ancillary data were obtained from the related documents and publications wherever feasible.

\section{Post field work}

In the post field work, the building footprint map with ground shape of buildings was digitized with the help of Google Earth Pro tool and then the digital data were converted to Kml2shpv2_3. avx extension. The shape file was based on projection with the help of Arc View GIS 3.2a. In GIS, each building footprint was separated and given unique identity. All attribute data and information of the buildings gathered from the sheet were processed by excel format and then converted into dbase file as compatible to GIS and joined with the attribute table. After completion of the GIS work, buildings vulnerability analysis was done. Vulnerability functions were performed to describing the relation between seismic intensity and damage rate of the building types. Each building's vulnerability level was calculated by comparing different building parameters like age, structure, geometry, height of the buildings etc. with the help of the Damage Grade Matrix. 


\section{Results and Discussion}

\section{Characteristics of building}

Earthquakes do not kill people but unsafe buildings do kill the people. So to identify the building vulnerability, it is necessary to know the buildings' physical characteristics. Seismic vulnerability of building is highly dependent on the space between buildings, age of building, geometry of buildings, materials used, buildings' height, and technology used. A brief description of the buildings in Dhankuta municipality is made here. Since the study was focused on determining the building vulnerability during an earthquake episode it is important to have information of the buildings where people live. Figure 4 shows the building foot-print of Dhankuta municipality.

In Dhankuta, there were 4,287 total buildings with their 7,849 separate floors. About 83 percent of all floors were used for residential

Figure 4: Building distribution

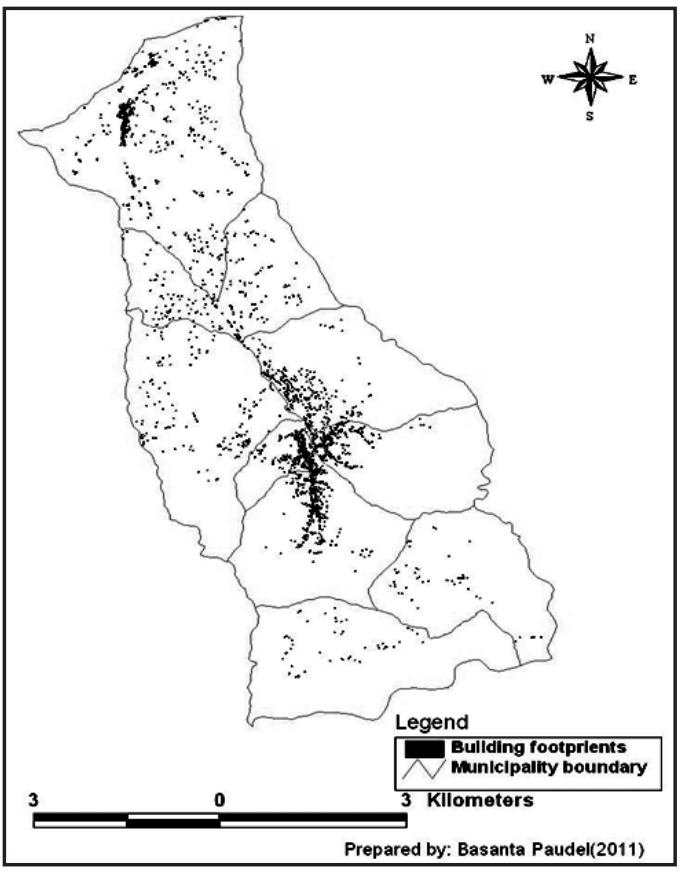
purpose, 7.86 percent for commercial, 3.81 percent for office/institute, 2.70 percent for school/ campus, 1.57 percent for hotel/restaurant and 1.27 percent for different purposes (See Table 2).

Most of the ground and the first floors found to be used for commercial and residential purposes with about 71 percent and 50 percent respectively. Similarly 61 percent of schools/campuses, 49 percent of offices/institutes and 50 percent of hotel/restaurants used the ground floor.

Table 2: Building floors classified by space use

\begin{tabular}{lrrrrrrrrrrrrrrrr}
\hline \multirow{2}{*}{ Floor } & \multicolumn{1}{c}{ CO } & No & $\%$ & No & $\%$ & No & $\%$ & No & $\%$ & No & $\%$ & No & $\%$ & No & $\%$ \\
\hline 0 & 439 & 71.15 & 3432 & 52.82 & 130 & 61.32 & 146 & 48.83 & 61 & 49.59 & 79 & 79 & 4287 & 54.62 \\
1 st & 168 & 27.23 & 2733 & 42.06 & 70 & 33.02 & 115 & 38.46 & 45 & 36.59 & 19 & 19 & 3150 & 40.13 \\
$2^{\text {nd }}$ & 8 & 1.29 & 319 & 4.91 & 12 & 5.66 & 32 & 10.70 & 16 & 13.01 & 2 & 2 & 389 & 4.96 \\
$3^{\text {rd }}$ & 2 & 0.33 & 9 & 0.13 & 0 & 0 & 4 & 1.34 & 1 & 0.81 & 0 & 0 & 16 & 0.20 \\
$4^{\text {th }}$ & 0 & 0 & 2 & 0.03 & 0 & 0 & 2 & 0.67 & 0 & 0 & 0 & 0 & 4 & 0.05 \\
$5^{\text {th }}$ & 0 & 0 & 2 & 0.03 & 0 & 0 & 0 & 0 & 0 & 0 & 0 & 0 & 2 & 0.03 \\
$6^{\text {th }}$ & 0 & 0 & 1 & 0.02 & 0 & 0 & 0 & 0 & 0 & 0 & 0 & 0 & 1 & 0.01 \\
\hline Total & 617 & 100 & 6498 & 100 & 212 & 100 & 299 & 100 & 123 & 100 & 100 & 100 & 7849 & 100 \\
$\%$ & 7.86 & & 82.79 & & 2.70 & & 3.81 & & 1.57 & & 1.27 & & 100 & \\
\hline
\end{tabular}

Source: Field survey 2011

Note: $\mathrm{CO}=$ Commercial, $\mathrm{RS}=$ Residential, $\mathrm{SC}=$ School/Campus, $\mathrm{OI}=$ Office/Institution, $\mathrm{HR}=$ Hotel/Restaurant, Others $=$ (Hospital, police/ army station, industry and mixed used floors). 
The building age was classified into three categories to find out whether they were old or newly constructed. For example, building aged less than 20 years was defined as new building and the buildings were made by brick with cement and reinforce concrete, those with 20-50 years were categorized as old buildings, which were generally made by brick in mud or stone in mud, and lastly, buildings with over 50 years of age were known as oldest buildings (Fig. 5).

Figure 5: Age classification of buildings

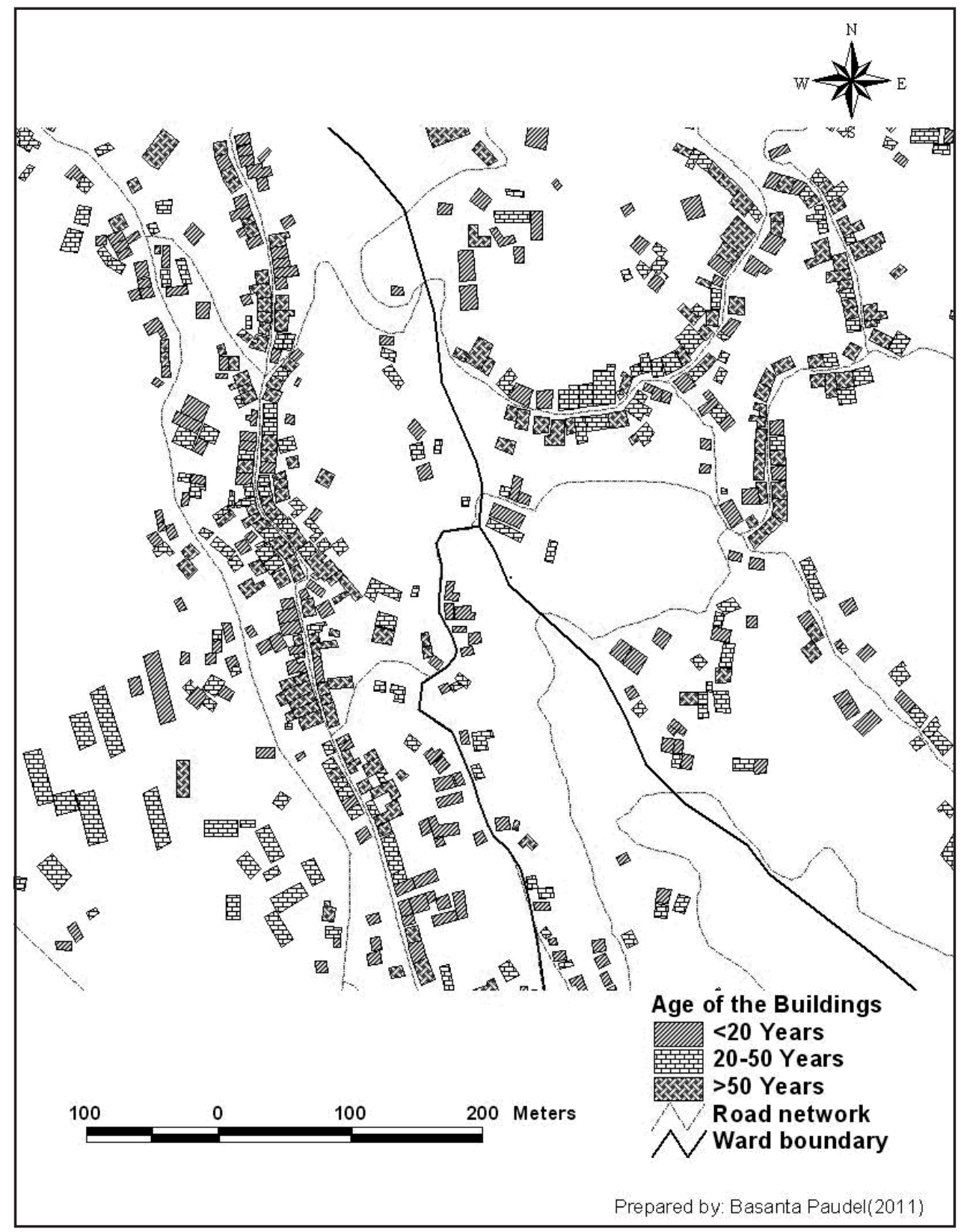


Out of 4,287 buildings, 1,706 (or $39.79 \%$ ) were newly built buildings; 51.36 percent were old and 8.85 percent with over 50 years of age were oldest.

Similarly, the percentile distribution of building types was as follows: stone with mud - 29.34; brick with mud - 23; brick with cement - 18.54; reinforce cement concrete - 13.30; adobe - 7.67; stone with cement 6.93 , and wooden buildings -1.22 .

\section{Vulnerability assessment of the building}

\section{Building vulnerability}

The vulnerability classes, viz. high, medium and low for the individual buildings were obtained by using the weightage assigned to each building based on vulnerability parameters. The vulnerability ranges from 0 to 1 . Thus, the three levels of vulnerability were defined as: low with $0-0.20$, medium $0.20-0.50$ and high with $>0.50$. Finally, the range level of the vulnerability was used to calculate the damage and collapse probability of individual buildings with reference to building damage grid matrix and intensity of the earthquake.

Table 3 reveals that 72.52 percent buildings found to be in low vulnerability, whereas high vulnerability accounted for only 0.68 percent. According to construction materials, 295 of the total adobe buildings found to be in low vulnerability class, 33 medium and only one building in high vulnerability class.

Table 3: Classification vulnerability of building by type

\begin{tabular}{lrrrr}
\hline \multirow{2}{*}{ Buildings type } & \multicolumn{4}{c}{ Vulnerability classes } \\
\cline { 2 - 5 } & Low & Medium & High & Total \\
\hline Adobe & 295 & 33 & 1 & 329 \\
Brick + mud & 513 & 277 & 5 & 795 \\
Brick + cement & 625 & 342 & 19 & 986 \\
Stone + mud & 177 & 117 & 3 & 297 \\
Stone + cement & 1034 & 223 & 1 & 1258 \\
Wood & 27 & 25 & 0 & 52 \\
Reinforce cement concrete & 438 & 132 & 0 & 570 \\
\hline Total & 3109 & 1149 & 29 & 4287 \\
Percent & 72.52 & 26.80 & 0.68 & 100 \\
\hline
\end{tabular}

Source: Field survey 2011 
Figure 6 and Table 4 show details of vulnerability level of building structure type.

Figure 6: Classification vulnerability of buildings

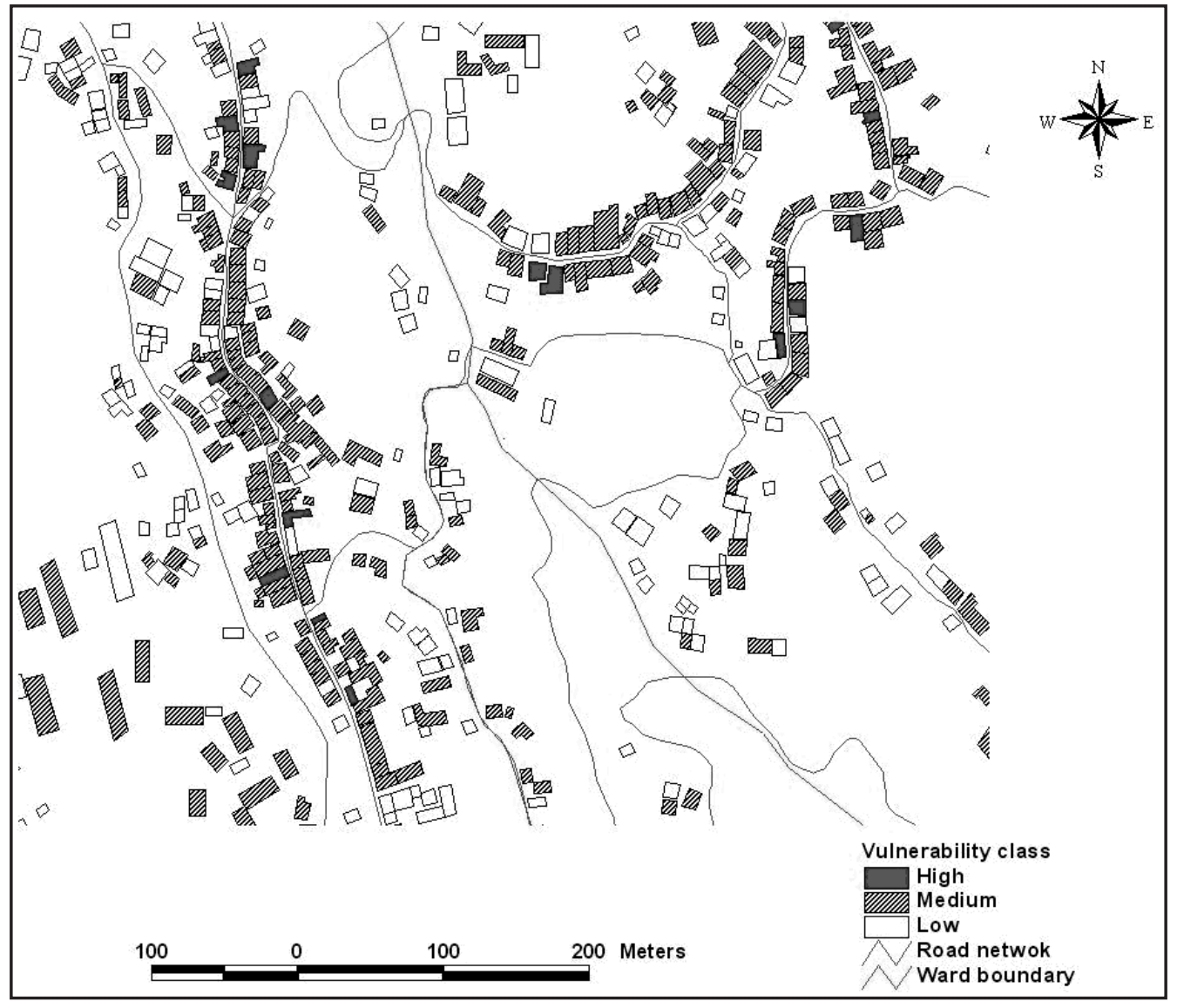

\section{Probable building damage of earthquake scenario}

As stated above, the Udayapur Earthquake scenario is considered one of the possible earthquakes with huge magnitude of 8.0 Richter scale. It is anticipated to occur due to the active main boundary thrust fault which lies about $33.0 \mathrm{~km}$ corresponding south-west from Dhankuta municipality. Table 4 exhibits five levels of damage or collapse under "Intensity VIII" and that $14.21 \%$ of the total buildings fell in the category of heavy damage or total collapse, whereas the largest share with $43.57 \%$ buildings fell in the partially damage class (such as gaps in wall, collapse of parts of the building). Under the "Intensity VII", 2.23 percent of the buildings fell in "DG 3", i.e. heavy damage. DG "0" includes buildings with reinforce of Cement Concrete, which were mostly related to two floors and possibly might have negligible or no visible effect by the earthquake. This has been measured based on educative judgment of the researcher, which is shown in Figure 7. 
Table 4: Building damage grade (DG) in different intensity of earthquake scenario

\begin{tabular}{lrrrrrr|rrrrrrr}
\hline \multirow{2}{*}{ Building type } & \multicolumn{7}{c|}{ Intensity VIII (DG) } & \multicolumn{7}{c}{ Intensity VII (DG) } \\
\cline { 2 - 14 } & 0 & 1 & 2 & 3 & 4 & 5 & 0 & 1 & 2 & 3 & 4 & 5 & Total \\
\hline Adobe & 0 & 0 & 0 & 0 & 275 & 32 & 0 & 0 & 0 & 20 & 2 & 0 & 329 \\
Brick in cement & 0 & 0 & 502 & 277 & 5 & 0 & 0 & 11 & 0 & 0 & 0 & 0 & 795 \\
Brick in mud & 0 & 0 & 0 & 0 & 595 & 358 & 0 & 0 & 0 & 30 & 3 & 0 & 986 \\
Stone in cement & 0 & 0 & 174 & 116 & 3 & 0 & 0 & 3 & 1 & 54 & 0 & 0 & 297 \\
Stone in mud & 0 & & 0 & 0 & 980 & 219 & 0 & 0 & 0 & 0 & 5 & 0 & 1258 \\
Wood & & 27 & 25 & 0 & 0 & 0 & 0 & 0 & 0 & 0 & 0 & 0 & \\
Reinforce Cement Concrete & 0 & 435 & 132 & 0 & 0 & 0 & 3 & 0 & 0 & 0 & 0 & 0 & 52 \\
\hline Total & 0 & 462 & 833 & 393 & 1858 & 609 & 3 & 14 & 1 & 104 & 10 & 0 & 4287 \\
\hline
\end{tabular}

Source: Field survey 2011

Note: DG 0: "No Visible effect", DG 1: "Slight Damage", DG 2: "Moderate Damage", DG 3: "Heavy Damage", DG 4: "Destruction" and DG 5: "Total damage/Collapse".

Figure 7: Damage grade of buildings under the "Intensity VIII" of earthquake scenario

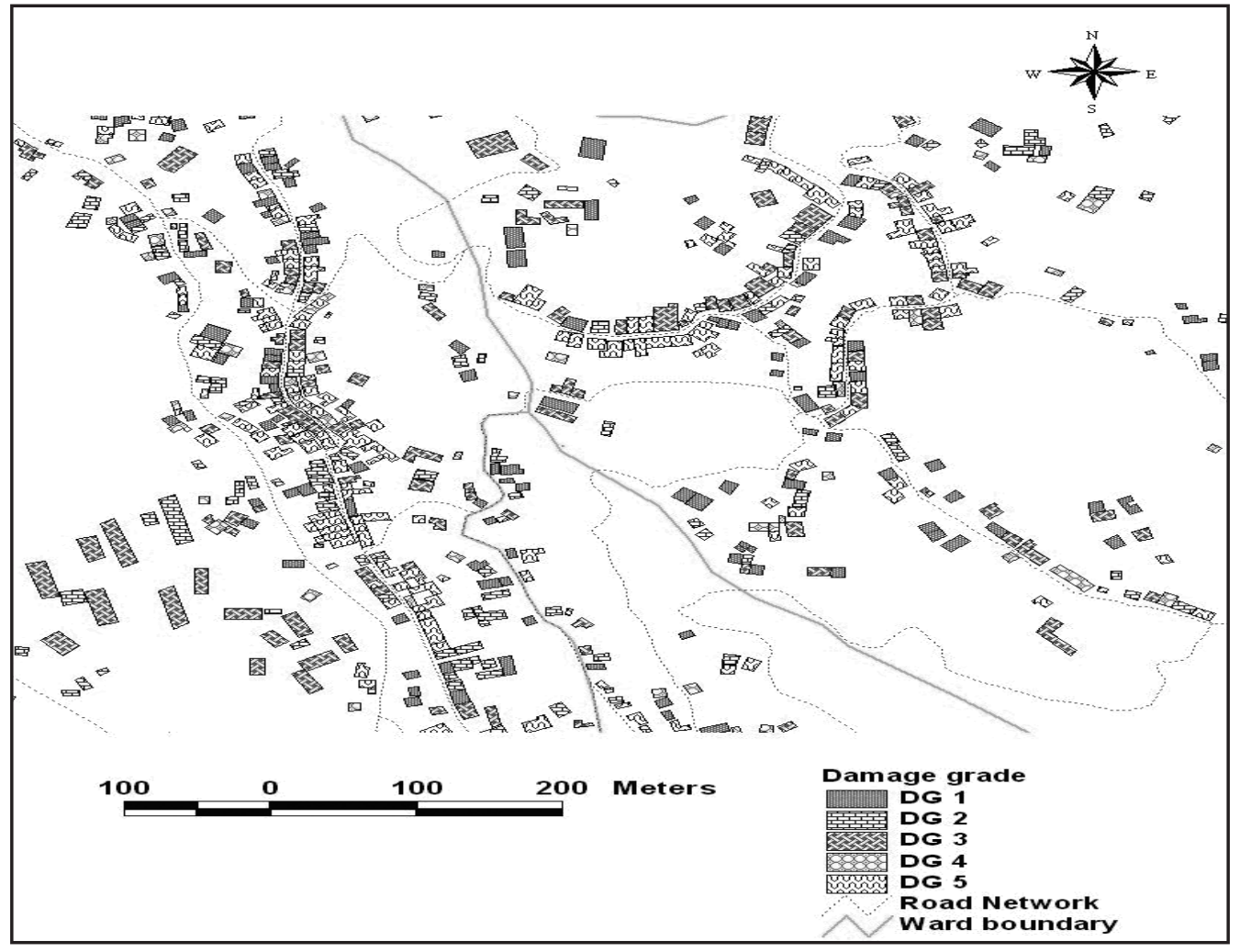

Probable damage of school/campus, hospital and office/institute

School/campus is a social center of people of both rural and urban areas. School/campus can be important to provide effective awareness programme to the community. Budget, which is crucial for school management, is usually low. On the other hand, they can be a shelter for the 
deliverance in the time of earthquake period. Such public schools/campuses built up with brick in cement, brick in mud and stone in mud without engineering design will have more chance to be damaged and collapsed by earthquake. Hospital is an important center for treatment of injured patient. It is more important to preserve the public life at the time of earthquake, so it must be well constructed.

Based on our calculation, 5 out of total 130 schools/campus buildings found to be possibly damaged and 125 buildings could be partially damaged, if earthquake occurs. Relatively greater damage may occur in the office buildings, as 7 and 138 out of 145 total might probably be totally damaged and partially damaged respectively. All 4 hospital buildings would not collapse but might have partial damage.

\section{Factors of Increasing Building Vulnerability}

Seismic vulnerability of a building is the amount of expected damage induced to it by a particular level of earthquake intensity. It describes the probability of failure of buildings under different levels of ground shaking and is expressed as a percent loss caused by a particular seismic hazard to the type of building under consideration (UNDP 1994).

The extent of damage to a building depends on strength, ductility, and integrity of a building and the stiffness of ground beneath it in a given intensity of the earthquake motions (IAEE and IIT 2004). Ambrose and Vergun (1999 cited in Guragain 2004) stated that the amount of damage to buildings caused by an earthquake depends upon the amount of acceleration, velocity and displacement experienced at a particular site created by the earthquake and the strength of the buildings to resist these forces. Thus, it can be safely said that the characters of the building itself such as construction method, materials used, building configuration in plan and in elevation, age, number of storey, size of the buildings etc are responsible for the damage of the buildings.

The factors that affect the building vulnerability can be divided into primary and secondary levels (UNDP 1994). Primary factors include sub-soil condition and building construction materials, whereas secondary factors are those associated with the inherent deficiencies of a particular building (like shape, size, height, age, construction quality, etc). On the effect of such secondary factors - buildings with the same material type but different shape in plan, elevation, size, height, age or construction quality would show different behavior at the same site. The factors responsible for increasing risk of buildings by earthquake hazard are based mainly on building structure (frame structure, load bearing structure, dual structure), structural bands (plinth band, lintel band, roof band, and gable band), building shape, building height, building separation distance and building materials. These factors are important to be considered in case of Dhankuta while giving permission to new buildings, as well as in other towns and cities of Nepal.

\section{Conclusions}

The probability of damage and collapse of the buildings or building vulnerability is highly dependent on its physical condition as well as other building parameters. However, while the earth vibration depends on the geological condition, loss of buildings is closely related to the earth vibration during earthquake period. So weak geological condition and weak building construction materials are the factors to increase probability of damage or collapse of buildings. This study considers the building vulnerability in different earthquake scenario assuming in different intensities. 
The results show that most of the buildings have high probability of damage or collapse by a strong earthquake with an intensity of VIII in Dhankuta. Mainly the buildings of the core area of the municipality including Hile bazaar area, Mathillo Kopche, Tallo Kopche, Bich bazaar, Siran bazaar area, Hulak tole, and Madan Chowk areas are highly probable areas for the loss or collapse of buildings, where the density of buildings is closely spaced compared to other areas.

The factors responsible for increasing risk of buildings by earthquake hazard include building structure (frame structure, load bearing structure, dual structure), structural bands (plinth band, lintel band, roof band, and gable band), building shape, building height, building separation distance and building materials. The rigorous field methods combined with GIS analysis to generating various map layers showing vulnerability degree adopted here have proven a fairly reliable methodology for earthquake hazard estimation analysis in Nepal. It is also argued that, earthquake hazard has a direct relation with poverty and awareness. The latter is to be considered very crucial and adopted very effectively so that probable loss of lives and properties such as buildings can be saved.

\section{References}

BCDP (2008), Seismic fault line in Nepal. Kathmandu: Building Code Development Project.

Guragain, J. (2004), GIS for Seismic Building Loss Estimation: A Case Study of Lalitpur Sub Metropolitan City. M. Sc thesis, International Institute for Geo-Information and Earth Observation (ITC), Enschede, Netherlands.

IAEE and IIT (2004), Guidelines for Earthquake Resistant Non- Engineered Construction. IIT Kanpur. National Information Centre of Earthquake Engineering.

ISRC (2008), Municipality Profile of Nepal 2008. Kathmandu: Intensive Study and Research Center.

Khanal, N.R. (1996), Assessment of Natural Hazards in Nepal. A Report submitted to Research Division, T.U., Kirtipur, Nepal.

Lake, P. (2006), Physical Geography. Delhi: Surjeet Publication.

NGIIP (1998), Digital layer map of Dhankuta Municipality in GIS Environment. Kathmandu: National Geographic Information Infrastructure Programme, Department of Survey.

NSET (2004), Disaster Inventory/Information Management System in Nepal. Kathmandu. National Society for Earthquake Technology (NSET) Nepal.

Pandey, M.R. (1999), Resource materials for regional training course on landslide hazard management and control in the Hindu Kush Himalaya Region (12 September- 2 October, 1999, Kathmandu Nepal). Earthquakes and Landslides. Vol. III: lecture notes, Kathmandu: ICIMOD.

RUPP (2008), Digital layer map of Dhankuta municipality in GIS Environment. Kathmandu, Rural Urban Partnership Programme.

Timsina, C. (2011), Seismic Hazard Analysis of Dhankuta Municipality Eastern Nepal. M. Sc. thesis, Central Department of Geology, T.U.

UNDP (2004), Living with Risk: A global review of disaster reduction initiatives. Geneva: United Nations Development Program, United Nations Publications.

UNDP (1994), Development of Alternative Building Materials and Technologies. Government of Nepal, Ministry of Housing and Physical Planning. UNDP/UNCHS Habitat.

UNDP (1994), Seismic Hazard Mapping and Risk Assessment for Nepal. Government of Nepal, Ministry of Housing and Physical Planning. UNDP/UNCHS Habitat.

www.seismo.ethz.ch/GSHAP/(Retrieved on 2 January, 2011). 